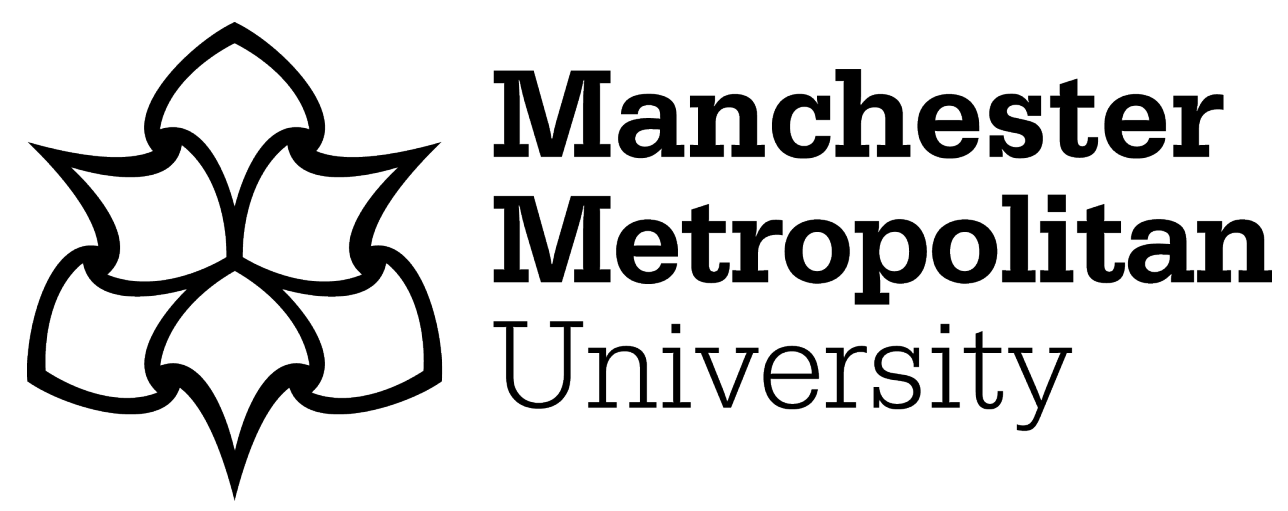

Burns, E, Wolff, G, Jeffreys, R, Sparkes, R, Guustafsson, O, Wild, B, Semiletov, I and Van Dongen, B (2019) Fate of terrigenous nitrogen in East Siberian Arctic shelf sediments. In: Proceedings: 29th International Meeting on Organic Geochemistry, IMOG 2019, 01 September 2019 - 06 September 2019, Gothenburg, Sweden.

Downloaded from: https://e-space.mmu.ac.uk/624554/

Publisher: European Association of Geoscientists \& Engineers

DOI: https://doi.org/10.3997/2214-4609.201903035

Please cite the published version 


\title{
FATE OF TERRIGENOUS NITROGEN IN EAST SIBERIAN ARCTIC SHELF
}

\section{SEDIMENTS}

\author{
E. Burns ${ }^{1}$, G. Wolff ${ }^{2}$, R. Jeffreys ${ }^{2}$, R. Sparkes ${ }^{3}$, Ö. Gustafsson ${ }^{4}$,B. Wild ${ }^{4}$, I. Semiletov ${ }^{5}$, B. \\ van Dongen ${ }^{1}$
}

${ }^{1}$ University of Manchester, UK. ${ }^{2}$ University of Liverpool, UK. ${ }^{3}$ Manchester Metropolitan University, UK. ${ }^{4}$ Stockholm University, Sweden. ${ }^{5}$ University of Tomsk, Russia

\section{Introduction}

Climate warming in the East Siberian Arctic region has caused enhanced transport of large amounts of 'old' terrigenous organic matter (OM), previously stored for thousands of years in the (thawing) Siberian permafrost, to the East Siberian Arctic Seas (ESAS; Vonk et al., 2012). Although major progress has been made in the last decades, the fate of the organic carbon component of this remobilised terrigenous $\mathrm{OM}$ is still a matter of debate. Recent studies, for instance, indicate that (i) there are large differences in the degradation of different compound classes and fractions (e.g. dissolved vs particulate OM) and (ii) matrix association of these compounds exerts a first order control over their degradability (Sánchez-García et al., 2011; Karlsson et al., 2016; Sparkes et al., 2016; Tesi et al., 2016). A substantial part of the remobilised terrigenous organic carbon is degraded in the Arctic shelf water column and released into the atmosphere, particularly close to the point of origin, e.g. river outflow or coastal erosion of organic rich Pleistocene permafrost ice complex deposits, leading to a further positive feedback for global climate warming (Vonk et al., 2012; Vonk and Gustafsson, 2013; Bröder et al., 2016).

In contrast much less is known about the fate of the terrigenous organic nitrogen (TON) in this region. An understanding of the fate of this TON is important as nitrogen is a limiting nutrient for phytoplankton growth. Changes in the availability and source of this nutrient element can affect the Arctic food web from the base upwards (Batista et al., 2014). These changes can be detected through the food web by both bulk and compound specific stable analysis (e.g. Carstens et al., 2013).

\section{Results and discussion}

In this study bulk $\delta^{15} \mathrm{~N}$ values (inorganic and organic nitrogen) were obtained from analyses of surface sediments collected over extensive scales of the ESAS (Laptev Sea, Dmitry Laptev Strait and East Siberian Sea) during the ISSS-08 (2008) and SWERUS-C3 (2014) cruises. The $\delta^{15} \mathrm{~N}$ signature shows a near shore region dominated by river input and coastal erosion, in contrast, further offshore the $\delta^{15} \mathrm{~N}$ signature is primarily marine. Comparison of bulk $\delta^{15} \mathrm{~N}$ and $\delta^{13} \mathrm{C}$ values show a strong correlation suggesting a comparable fate for the terrigenous nitrogen and organic carbon in these Arctic regions (figure 1a). Based on the sediments from the near coastal regions, distinct $\delta^{15} \mathrm{~N}$ terrigenous endmembers values can be deduced, suggesting values for the Laptev Sea between 1.4 and 3.6\%o and for the East Siberian Sea between 4.2 and 6.7\%o, reflecting a difference in the terrigenous (organic) nitrogen input in these adjacent regions. This offset is continued in an offshore direction, suggesting that the remobilised terrigenous nitrogen is likely incorporated into the marine biomass. Macromolecular analysis (by pyrolysis GCMS) using a phenol to pyridine ratio (Sparkes et al., 2016) confirms the dominance of terrigenous derived OM in the coastal areas 
as well as the shifts to a marine dominance in off-shore directions. Comparison of bulk $\delta^{15} \mathrm{~N}$ and this ratio also shows a strong correlation, confirming not only the comparable fate of terrigenous nitrogen and $\mathrm{OM}$ in these regions but also supports the distinct differences observed between the Laptev and East Siberian Sea (figure 1b).

\section{Conclusions}

These results suggest that the ${ }^{15} \mathrm{~N}$ values at the base of the marine food web are influenced by the remobilised terrigenous nitrogen transported to these Arctic shelves. Ultimately, this could have a larger impact on the marine ${ }^{15} \mathrm{~N}$ isotope landscape and subsequently higher trophic levels within the Arctic Ocean food web than previously thought. However, in order to elucidate the source of the organic nitrogen fraction, e.g. excluding the potential impact of inorganic nitrogen sources, detailed compound specific (amino acid) $\delta^{15} \mathrm{~N}$ analyses are needed.
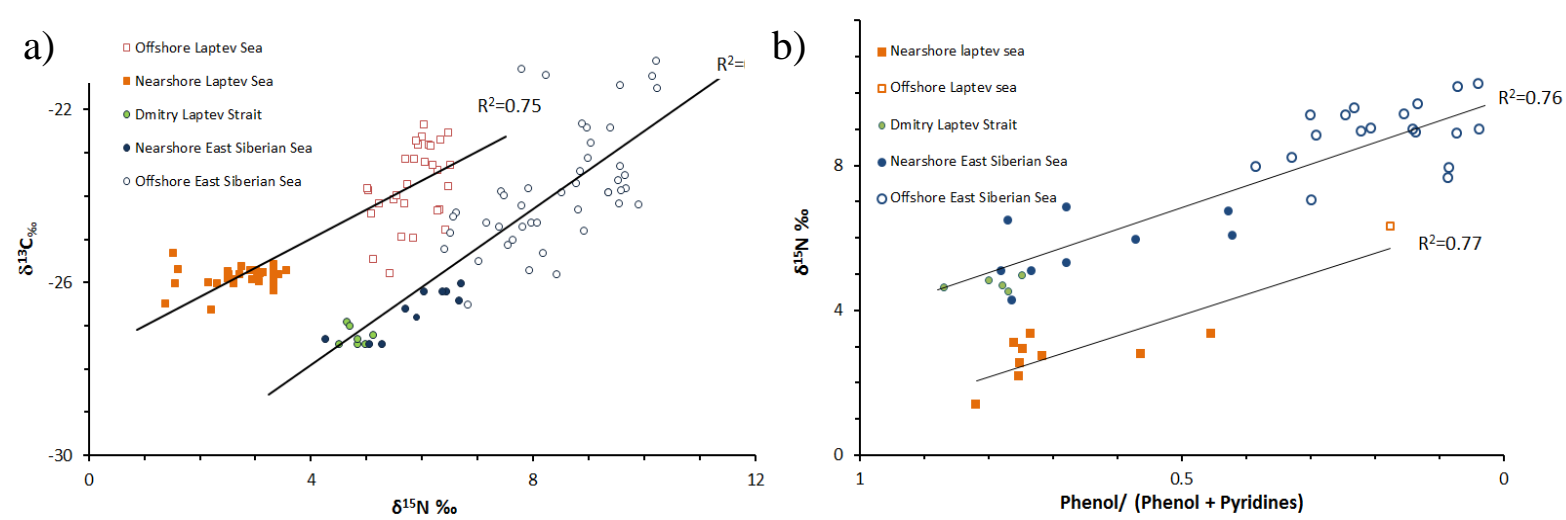

Figure 1 Plots of a) $\delta^{13} C$ vs $\delta^{15} N$ and $b$ ) $\delta^{15} N$ vs the phenol to pyridine ratio (obtained by pyGCMS) in surface sediments of the East Siberian Arctic Seas.

\section{References}

Batista, et al. (2014) Compound specific amino acid $\delta 15 \mathrm{~N}$ in marine sediments: A new approach for studies of the marine nitrogen cycle', Geochimica et Cosmochimica Acta, 142, 553-569.

Bröder, et al. (2016) Fate of terrigenous organic matter across the Laptev Sea from the mouth of the Lena River to the deep sea of the Arctic interior, Biogeosciences, 13, 5003-5019.

Carstens, et al. (2013) Amino acid nitrogen isotopic composition patterns in lacustrine sedimenting matter, Geochimica et Cosmochimica Acta. 121, 328-338.

Karlsson, et al. (2016) Different sources and degradation state of dissolved, particulate, and sedimentary organic matter along the Eurasian Arctic coastal margin, Global Biogeochemical Cycles, 898-919

Sánchez-García, et al. (2011) Inventories and behavior of particulate organic carbon in the Laptev and East Siberian seas, Global Biogeochemical Cycles, 25

Sparkes, et al. (2016) Macromolecular composition of terrestrial and marine organic matter in sediments across the East Siberian Arctic Shelf, Cryosphere, 10, 2485-2500.

Tesi, et al. (2016) Matrix association effects on hydrodynamic sorting and degradation of terrestrial organic matter during cross-shelf transport in the Laptev and East Siberian shelf seas, Journal of Geophysical Research: Biogeosciences, 121, 731-752.

Vonk, et al. (2012) Activation of old carbon by erosion of coastal and subsea permafrost in Arctic Siberia, Nature, 489, 137-140.

Vonk, J. E. and Gustafsson, Ö. (2013) Permafrost-carbon complexities', Nature Geoscience, 6, 675-676. 